\title{
Use of thermography for estimation water jet of the radiators in central heating system by Zbigniew Rymarczyk
}

Institute of Heating and Sanitary Technology, 26-600 Radom,ul. Wilcza 8, E-mail: Rymarczyk@radom. medianet. $\mathrm{pl}$

\begin{abstract}
Absrtact:
In the report, the method of estimation of water jet with use of computer programme and thermography worked out on the basis of mathematical model heat exchange „radiator accommodation" and thermography is suggested. This program makes possible to estimate the temperature distribution along height of radiator, thermal power of radiator, average value of temperature surface on the base of the water jet and the temperature of surface in inflow area and others. This temperature has been determined on the basis of thermographic measurements. Next, it is compared to the temperature on the surface in outflow area obtained experimentally by means of thermography with suitable temperature on the basis of program calculations for the given water jets.
\end{abstract}

\section{Introduction}

Thus fare, in energetic audit, thermography has been used for estimation of thermal insulation of building envelopes. It is classical application of this method. The energetic audit should contain estimation of performance of central heating system as well. The combination of numerical method and thermography makes possible to estimate water jet in radiator. The numerical method is based on the mathematical model of heat exchange "radiator accommodation". The basic assumptions of this model are presented below.

\section{The basic assumptions of the mathematical model heat exchange „radiator - accommodation"}

The mathematical model used in numerical program follows fundamental assumptions [ 1 , 2, 3]:

- the heating medium is water,

- surfaces of cross - sections of water's canal of radiator are identical,

- surfaces of cross - sections of radiator's walls are identical,

- the film thermal resistance from water to surface and thermal resistance of the radiator's walls are negligible little in comparison with thermal resistance of the outside radiator's surface - accommodation.

The equalization of heat balance for an element of radiator, after neglecting the thermal conductivity, has form $[2,3]$

$$
\rho_{w} \cdot f_{w} \cdot c_{w} \cdot v \frac{\partial T}{\partial x}+\left(f_{s} \cdot \rho_{s} \cdot c_{s}+f_{w} \cdot \rho_{w} \cdot c_{w}\right) \frac{\partial T}{\partial \tau}=-\frac{F_{g}}{h} \cdot \Delta \phi_{W},
$$

where:

$\rho_{w}$ - density of water, $\left[\mathrm{kg} / \mathrm{m}^{3}\right]$

$f_{w}$ - surface of cross-section water's channel of radiator, $\left[\mathrm{m}^{2}\right]$

$v$ - velocity of water, $[\mathrm{m} / \mathrm{s}]$

$c_{w}$ - heat capacity of water per unit mass, $[\mathrm{J} /(\mathrm{kg} \mathrm{K})]$

$T$ - temperature of water, [K] 
$\lambda_{w}, \lambda_{s}$ - thermal conductivities of the water and wall's material of radiator respectively, $[\mathrm{W} /(\mathrm{m} \cdot \mathrm{K})]$

$f_{s}$ - surface of cross section of radiator's wall, [ $\left.\mathrm{m}^{2}\right]$,

$F_{g}$ - surface of outside surface of radiator, $\left[\mathrm{m}^{2}\right]$,

$h$ - height of radiator, $\mathrm{m}$.

If process of heat exchange "radiator - accommodation" describes relationships:

$$
\begin{aligned}
& \Delta \phi_{W}=\alpha_{k} \cdot\left(T-T_{a t m}\right)+\frac{F_{p}}{F_{g}}\left(\phi_{g}-\phi_{o}\right), \\
& \alpha_{k}=c_{k} \cdot\left(T-T_{a t m}\right)^{m}, \\
& \phi_{g}=\varepsilon_{g} \cdot \sigma \cdot(T+273,15)^{4},
\end{aligned}
$$

then, after substitutions of expressions (2), (3), (4) with (1), transformations and use of finite - difference method, the temperature along the height of radiator describes equalization $[2$, 3]

$$
T_{i}=b_{1} \bar{T}_{i}+b_{2} T_{i-1}-b_{3} \cdot\left(T_{i-1}-T_{W}\right)^{m+1}-b_{4} \cdot\left(273,15+T_{i-1}\right)^{4}+b_{5} \phi_{o},
$$

where:

$b_{1}, b_{2}, b_{3}, b_{4}, b_{5}-$ quantities connected with properties of water material and geometry of radiator,

$T_{i}, T_{i-1}$ - temperature in cross sections " $\mathrm{i}$ " and " $\mathrm{i}-1$ " in moment $\tau+\Delta \tau$,

$\bar{T}_{i}$ - temperature in cross-sections "i" in moment $\tau$,

$\phi_{o}-$ energy of radiation emitted from surface of accommodation to radiator,

$\phi_{g}$ - energy of radiation emitted from surface of radiator.

Assuming, $\Delta \tau \rightarrow \infty$, the relationship (5) has form used in the steady exchange of heat: $T_{i}=T_{i-1}-b_{3}^{\prime} \cdot\left(T_{i-1}-T_{a t m}\right)^{m+1}-b_{4}^{\prime} \cdot\left(273,15+T_{i-1}\right)^{4}+b_{5}^{\prime} \phi_{o}$,

where:

$$
\begin{aligned}
b_{3}^{\prime} & =\frac{F_{g} \cdot c_{k}}{G \cdot h \cdot c_{w}} \Delta x, \\
b_{4}^{\prime} & =\frac{F_{p} \cdot \varepsilon_{g} \cdot \sigma}{G \cdot h \cdot c_{w}} \Delta x, \\
b_{5}^{\prime} & =\frac{F_{p}}{G \cdot h \cdot c_{w} \cdot F_{g}} \Delta x,
\end{aligned}
$$

$F_{p}$-surface of radiator emitted radiation to accommodation, $\left[\mathrm{m}^{2}\right]$

$\varepsilon_{g}$ - emissivity of radiator's surface,

$\sigma$ - the Stefan - Boltzmann constant, $\left[\mathrm{W} /\left(\mathrm{m}^{2} \cdot \mathrm{K}^{4}\right)\right]$

$c_{k}, m$ - constants obtained experimentally (thermal examinations of radiators + thermography),

$G$ - water jet, [kg/s].

The thermal power of radiator can be expressed either as

$$
\Phi=G \cdot c_{w} \sum_{i=1}^{i=n}\left[T_{i-1}-T_{i}\right],[\mathrm{W}]
$$

or

$$
\Phi=G \cdot c_{w} \sum_{i=1}^{i=n}\left[b_{3}^{\prime} \cdot\left(T_{i-1}-T_{W}\right)^{m+1}+b_{4}^{\prime} \cdot\left(273,15+T_{i-1}\right)^{4}-b_{5}^{\prime} \phi_{o j}\right] .
$$


On the basis of mathematical model of the heat exchange computer programme has been worked out [4]. This programme makes possible to estimate:

- the temperature distribution along the height of radiator

- the thermal power of radiator

- the average value of temperature on radiator's surface.

\section{Method}

On the basis of thermographic and thermal measurements of the radiator, the computer programme is "calibrated". Thermographic and thermal examinations are worked out in the station of thermal examinations of radiators with open chamber. The measuring accuracy of the station was estimated on the basis of examinations in the certificated Testing Laboratory in Radom, which is in conformance with the standard PN-EN 45001 and ISO/IEC Guide $25: 1990$. The fitting coefficient " $c_{k}$ " (equation (7)) was chosen for the case when we know the temperature of inflow zone of radiator [2]

The conjuction between temperature distribution on the radiator and water jet makes using thermography possible and the mathematical model to qualifications of water jet. Iterative method presented in Fig. 1 was used in work [2]. On the base of thermographic measurements the temperature distribution on the radiator was evaluated, especially temperature in inflow and outflow zones. Next, in numerical program water jet was being changed, with the given step $k_{r}$, as long as temperature of surface of outflow zone, measured and counted by means of computer programme, have the same values.

\section{Results}

In Fig. 2, thermal pictures of steel panel radiator DE'LONGHI type 10 are presented for two values of water jet. They show the conjunction between the temperature of distribution on the radiator and water jet. Theoretical and experimental temperature of distribution for two values of water jets are presented in Fig 3. The values of thermal power and average temperature of radiator obtained with the aid of "calibrated" programme for two values jets (Fig 1 and 2) are: $673 \mathrm{~W}, 790 \mathrm{~W}$ and $70,2^{\circ} \mathrm{C}, 76,5^{\circ} \mathrm{C}$. Experimentally appointed values are respectively: $(714 \pm 6) \mathrm{W},(790 \pm 6) \mathrm{W}$ and $(70 \pm 0,5){ }^{\circ} \mathrm{C},(76.2 \pm 0,5){ }^{\circ} \mathrm{C}$ [2].

Thermal images of cast - iron radiator before cleaning of central heating installation and just after are presented in Fig. 4.

In Table1, the results of thermographic measurements and calculations, with the aid of the programme, are presented in quantitative forms.

The magnitudes obtained with the aid of thermography are: the temperature of surface of radiator in inflow $\left(\vartheta_{1, \dot{s} r}\right)$ and outflow $\left(\vartheta_{2, \dot{s} r}\right)$ zone, the average temperature $\left(\vartheta_{\dot{s} r}\right)$ of surface of radiator. The programme calculates: water jet $(G)$, thermal power $(\Phi)$, temperature of surface of radiator $\left(\vartheta_{2, \dot{s} r, m}\right)$. The deviations of temperature $\vartheta_{2, \dot{s} r}$ and $\vartheta_{2, \dot{s}, m}$, as well as $\vartheta_{\dot{s} r}$ and $\vartheta_{s r, m}$ are presented a well.

\section{Conclusions}

It is showed that estimation of water jet and thermal power on the grounds of numerical method and thermography is possible. This method is concerned with stationary heat exchange in configuration "radiator - accommodation”. The accuracy of measurements of water jet obtained before cleaning of installation is about $5 \%$ and after cleaning $13 \%$. In the case of thermal power, these values carried out properly are respectively: 1,6 and 3, 3 $\%$. The method of estimation of water jet and thermal power of radiators on the grounds of the programme and thermography can be used in diagnostics of elements of central heating 
installation in real objects. This method can be used in the case, when the assumption of steady heat exchange between radiator and environment is accepted. Moreover, the temperature distribution on the surface of radiator cannot be distorted by the anomal conditions of working of installation.

\section{Literature}

[1] RABJASZ, R," Statical and dynamic thermal properties of unit radiators ", scientific work The Warsaw University of Technology, Warsaw 1981 (in polish language)

[2] RYMARCZYK, Z., "Use of thermography to examinations of temperature distribution on surface of elements of central heating installation", doctor's thesis, Warsaw 1999 (in polish language)

[3] TURLEJSKI, S.," Model of heat exchange in water's systems of heating installations" , The Warsaw University of Technology, Warsaw 1982 (in polish language)

[4] TURLEJSKI, S.," Programme to thermal calculations of radiators", The Warsaw University of Technology, Warsaw 1982 (in polish language)

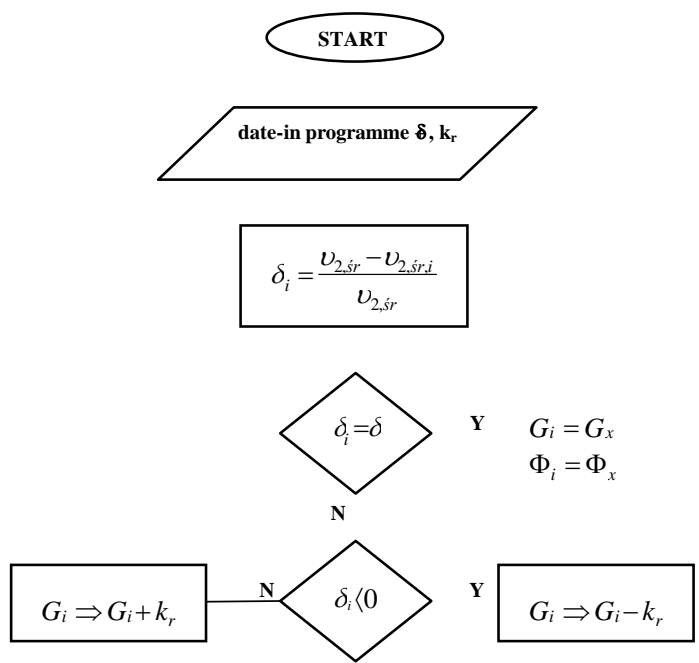

Figure 1: The algorithm of evaluation of water jet and thermal power of radiators

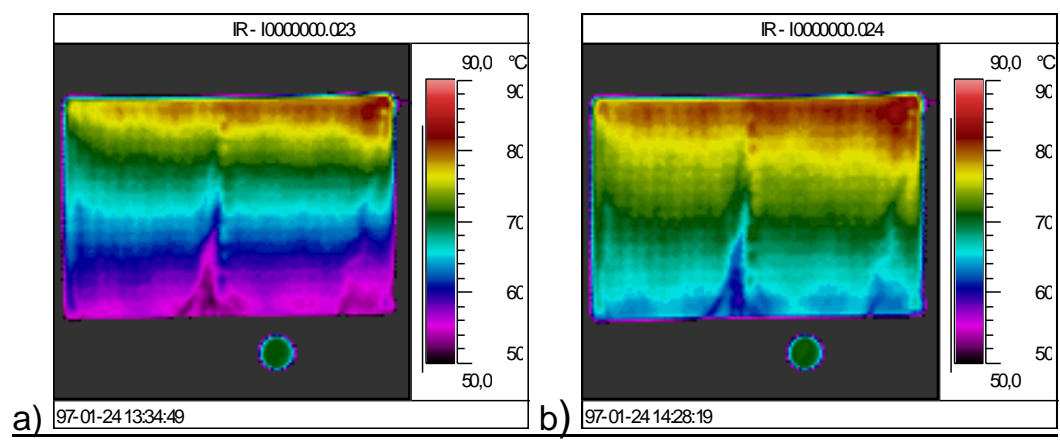

Figure 2: Thermograms of radiator DE' LONGHI type 10: water jet $0,00563 \mathrm{~kg} / \mathrm{s} \mathrm{b}$ ) water jet $\underline{0,00930 \mathrm{~kg} / \mathrm{s}}$ 
a)

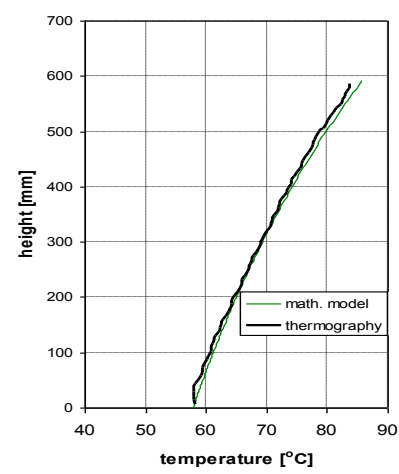

b)

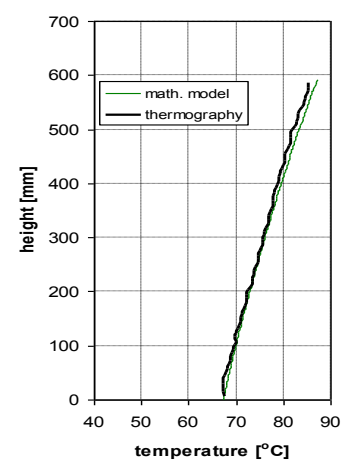

Figure 3: Graphs of temperature along height of radiator DE' LONGHI type 10 obtained for a) water jets $0,00563 \mathrm{~kg} / \mathrm{s} \mathrm{b}) 0,00930 \mathrm{~kg} / \mathrm{s}$ with the aid of the programme and thermography

a)

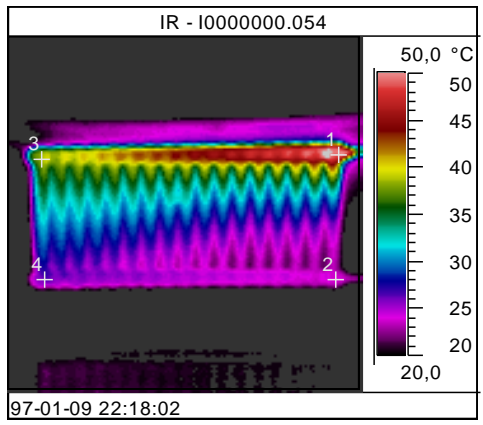

b)

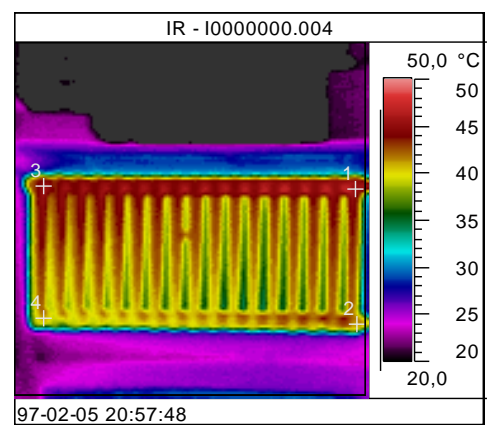

Figure 4: Thermograms of cast - iron radiator a) before cleaning $\mathrm{b}$ ) after cleaning

Table 1

Results of measurements and calculations for radiator

\begin{tabular}{|c|c|c|c|c|c|c|c|c|c|}
\hline $\begin{array}{c}\vartheta_{1, s r} \\
{\left[{ }^{\circ} \mathrm{C}\right]}\end{array}$ & $\begin{array}{c}\vartheta_{2, s r} \\
{\left[{ }^{\circ} \mathrm{C}\right]}\end{array}$ & $\begin{array}{c}\vartheta_{\dot{s} r} \\
{\left[{ }^{\circ} \mathrm{C}\right]}\end{array}$ & $\begin{array}{c}t_{i} \\
{\left[{ }^{\circ} \mathrm{C}\right]}\end{array}$ & $\begin{array}{c}\dot{M} \\
{[\mathrm{~kg} / \mathrm{s}]}\end{array}$ & $\Phi$ & $\begin{array}{c}\vartheta_{2, s, m} \\
{[\mathrm{~W}]}\end{array}$ & $\begin{array}{c}\vartheta_{\dot{s}, m} \\
{\left[{ }^{\circ} \mathrm{C}\right]}\end{array}$ & $\begin{array}{c}\delta \\
{[\%]}\end{array}$ & $\begin{array}{c}\delta_{\dot{s} r} \\
{[\%]}\end{array}$ \\
\hline \multicolumn{8}{|c|}{ before cleaning } \\
\hline 49,3 & 23,9 & 31,0 & 15,5 & 0,00485 & 515 & 23,9 & 32,5 & 0,0 & $-4,8$ \\
\hline \multicolumn{8}{|c|}{ after cleaning } \\
\hline 45,5 & 41,8 & 42,1 & 22,5 & 0,0435 & 671 & 41,8 & 43,6 & 0,0 & $-3,6$ \\
\hline
\end{tabular}

